\title{
Comparision of two ventilation modes and their clinical implications in sick children
}

\author{
Anil Sachdev, Krishan Chugh, Dhiren Gupta, Shruti Agarwal
}

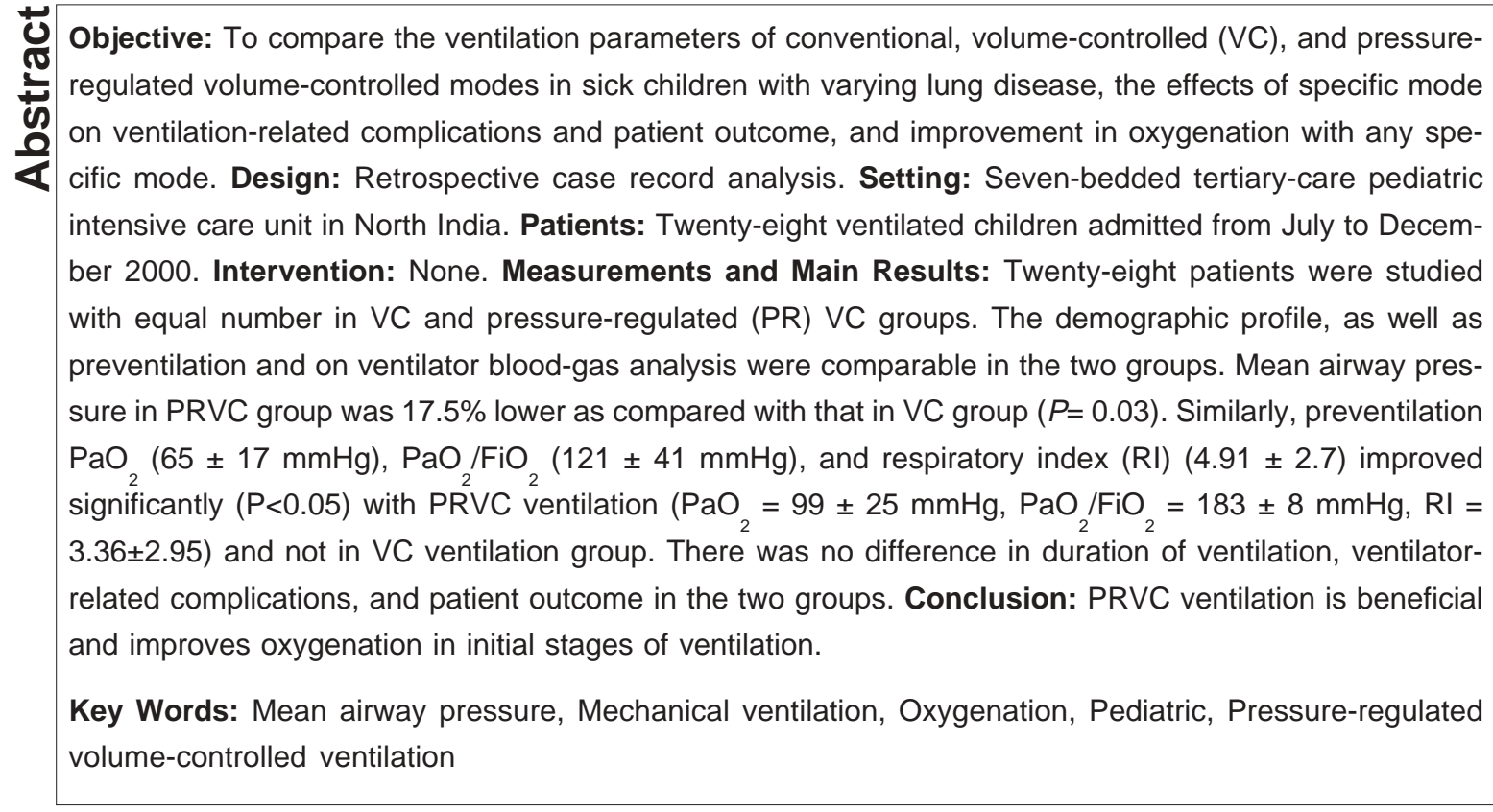

\section{Introduction}

Mechanical ventilation is a major part of pediatric critical care and is associated with significant morbidity, especially ventilator-induced lung injury. ${ }^{[1]}$ To circumvent these deleterious effects of mechanical ventilation, a variety of sophisticated and expensive methods have been developed. Conventional mechanical ventilations, volume-controlled (VC) or pressure controlled, are still the principal modes of ventilation used in all age groups. ${ }^{[2]}$ VC ventilation has the advantage of delivering a set tidal volume $(\mathrm{Vt})$, whatever peak inspiratory pressure (PIP)

\section{From:}

Sir Ganga Ram Hospital, Rajinder Nagar, New Delhi 110060, India

Correspondence:

Anil Sachdev, 63/12, Old Rajinder Nagar, New Delhi 110060, India. E-mail: anilcriticare@hotmail.com is required to deliver it, whereas in pressure-controlled ventilation delivered tidal volume varies with the compliance and resistance of thorax and lungs but the set peak pressure is not exceeded. In an attempt to make ventilation more patient friendly and gentler the PRVC ventilation was developed which has the distinct theoretical advantages of both VC and pressure-controlled ventilation. ${ }^{[3]}$ But very few studies are available in children to show a discernable clinical advantage of PRVC. Study by Kocis et al., ${ }^{[4]}$ comparing PRVC and VC, included only postoperative congenital heart disease and children with minimal lung disease, whereas Piotrowski et al. ${ }^{[5]}$ studied the use of PRVC in neonates only. This limits our understanding of use of PRVC in majority of children in pediatric intensive care unit (PICU) who have variety of lung pathologies of varying severity. 
This study was carried out in the sick children having varying degree of lung disease to compare (a) the ventilation parameters of conventional VC and PRVC ventilation in the initial ventilatory setting and (b) the effects of a specific mode on ventilation-related complications and patient outcome. In view of the distinct theoretical advantages of PRVC mode, it was hypothesized that PRVC would result in lower peak pressure and mean airway pressure with improvement in oxygenation.

\section{Materials and Methods}

This retrospective case record analysis was conducted in a multidisciplinary PICU of a tertiary-care hospital of a developing country. Case records of children with varied medical or surgical problems who were ventilated during a 6 months period beginning from July 2000 were analysed. During this period a total of 189 patients were admitted to the PICU and 44 children were ventilated. Sixteen patients were excluded from study. Eleven children received pressure-controlled ventilation and two were neonates whereas three patients received ventilation for less than $24 \mathrm{~h}$. These included one child of severe head injury with glassgow coma scale (GCS) of 3 and had cardiac arrest and was revived in emergency and died within $2 \mathrm{~h}$ of PICU admission. The other was an infant who had prolonged drowning at home and was received in PICU in post arrest state and died within a few hours. The third patient had laparotomy and had failed extubation and was transferred to PICU for postoperative care. She was successfully extubated within $1 \mathrm{~h}$ of arrival to PICU Twenty-eight patients were included in the study, with equal number in PRVC and VC groups. Patient characteristics including age, gender, clinical features, laboratory parameters, and Prismlll score ${ }^{[6]}$ at the time of admission and primary medical diagnosis were recorded (Table 1). The nonpulmonary cases in VC group had clinical, radiological, and blood-gas analysis evidence of pulmonary involvement. One case of meningoencephalitis had radiological evidence of aspiration pneumonia while patient of acute renal failure had pulmonary edema, hypoxemia, and right upper lobe atelectasis was seen in the child with infective polyneuritis. Platelet counts less than $2 \mathrm{lac} / \mathrm{mm}^{3}$ were recorded in 10 patients in VC group and in 8 cases in PRVC group. Seven children in VC group and six patients in PRVC group had prolonged prothrombin time and activated partial thromboplastin time.

\section{Table 1: Patient characteristic}

\begin{tabular}{|c|c|c|c|}
\hline & $\begin{array}{l}\text { VC } \\
(n=14)\end{array}$ & $\begin{array}{l}\text { PRVC } \\
(n=14)\end{array}$ & $\boldsymbol{P}$ \\
\hline Age (median; years) & 2 & 1.5 & \\
\hline $\mathrm{M}: \mathrm{F}$ & $10: 4$ & $12: 2$ & \\
\hline Shock & 6 & 5 & \\
\hline Altered sensorium & 9 & 9 & \\
\hline Seizures & 7 & 6 & \\
\hline Hemoglobin (g/dl) & $8.8 \pm 2.0^{a}$ & $9.5 \pm 1.4$ & 0.3 \\
\hline BUN (mg/dl) & $25 \pm 22.0$ & $16 \pm 8.0$ & 0.16 \\
\hline Creatinine (mg/dl) & $1.2 \pm 1.6$ & $0.7 \pm 0.3$ & 0.27 \\
\hline Calcium (mg/dl) & $8.3 \pm 1.0$ & $8.5 \pm 1.0$ & 0.53 \\
\hline Sodium (meq/l) & $137.5 \pm 5.5$ & $135.1 \pm 5.5$ & 0.09 \\
\hline Potassium (meq/l) & $4.4 \pm 0.0 .87$ & $4.0 \pm 0.58$ & 0.17 \\
\hline Blood glucose & $146.3 \pm 63.5$ & $137.2 \pm 59.1$ & 0.7 \\
\hline PRISM III score ${ }^{b}$ & $10(0-22)^{c}$ & $11(1-21)^{d}$ & \\
\hline \multicolumn{4}{|l|}{ Primary medical diagnosis } \\
\hline Pneumonia & 5 & 3 & \\
\hline Meningoencephalitis & 2 & 3 & \\
\hline Septicemia & 2 & - & \\
\hline Acute renal failure & 2 & - & \\
\hline Degenerative brain disease & 2 & - & \\
\hline Infective Polyneuritis & 1 & - & \\
\hline Cystic fibrosis & - & 2 & \\
\hline Bronchial asthma & - & 1 & \\
\hline Burns & - & 1 & \\
\hline Lung cyst & - & 1 & \\
\hline ARDS & - & 1 & \\
\hline Subdural hematoma & - & 2 & \\
\hline
\end{tabular}

ARDS, acute respiratory distress syndrome.

${ }^{a}$ Mean \pm SD.

${ }^{b}$ Median and range.

${ }^{c} n=11$.

${ }^{d}$ Blood urea nitrogen $(\mathrm{BUN})=12$.

Ventilation data-The criteria of placing a child with normal or abnormal lungs on mechanical ventilation in our unit include unprotected airway, increased work of breathing, high oxygen requirement $\left(\mathrm{FiO}_{2}>0.6\right), \mathrm{PaO}_{2}$ $<60 \mathrm{mmHg}, \mathrm{PaCO}_{2}>50 \mathrm{mmHg}$, and hemodynamic instability or resistant shock. As a protocol in PICU, decisions to start mechanical ventilation change in ventilator settings and timing and mode of weaning are taken by attending consultants (KC, AS) based on clinical features, bedside monitoring and arterial blood gas analysis (ABG) reports. In the present study equal number of patients received $P R V C$ and $V C$ ventilation but the choice of particular mode was determined by the availability of a particular machine (Siemens servo 900 for VC and Siemens 300 for PRVC). At the time of study, only four ventilators were available in this busy unit. On only two occasions both ventilators were available. So, on the discretion of consultant-in-charge, the mode was selected. All patients were sedated and paralyzed with a continuous infusion of midazolam and vecuronium. Prior to mechanical ventilation all patients were provided oxy- 
gen with an overhead box or with a venturi mask. Oxygen analyzer (Minion I MSA Medical products, Pittsburgh, USA) was used to measure $\mathrm{FiO}_{2}$ in overhead oxygen hood. Radial artery catheter was in place for sampling in all patients. Preventilation ABG reports were available in 11 and 12 children in VC and PRVC groups, respectively. Rest of the patients (i.e., five) were put on ventilator on the basis of clinical assessment. For this reason, Prismlll score and respiratory index $\left\{\mathrm{RI}=\mathrm{p}_{\text {alveolar }} \mathrm{O}_{2}\right.$ - $\left.\mathrm{p}_{\text {arterial }} \mathrm{O}_{2} / \mathrm{p}_{\text {arterial }} \mathrm{O}_{2}\right\}^{[7]}$ could not be calculated in these five patients. If more than one preventilation $A B G$ report was available, the one done immediately prior to starting ventilation was recorded. Ventilation data available from nursing charts were recorded. ABG report and ventilation setting recorded after initial stabilization (approximately $3-4$ h) was used for analysis. Initial stabilization included fluid therapy, blood glucose check, and oxygen therapy, and checks the response to interventions. If the patient's clinical condition was not moribund, $A B G$ report was checked before initiation of ventilation. As a policy in our unit, the ventilation settings are set at minimum to achieve $\mathrm{pO}_{2}$ between 60 and $90 \mathrm{mmHg}$ and $\mathrm{pCO}_{2}$ between 40 and $50 \mathrm{mmHg}$, whenever possible. Eight children in VC and nine cases in PRVC group were ventilated within $6 \mathrm{~h}$ of admission. Three patients in each group were ventilated within $12 \mathrm{~h}$ and rest of patients was initiated on ventilator after $24 \mathrm{~h}$ of admission. Medical records were also searched for mechanical ventilation related complications including air leaks, atelectasis, hyperinflation, and ventilation-associated pneumonia.

Statistical analysis - mean and standard deviation (SD) were calculated for each variable in both VC and PRVC group. Nonparametric tests and Mann-Whitney and Wilcoxon signed rank tests were used wherever applicable. $P<0.05$ was considered significant.

\section{Results}

Of the 28 patients studied, median age in VC group was 2 years (range 7 months to 7 years) and in PRVC group it was 1.5 years (range 2 months to 6 years). Preventilation and on ventilator ABG reports and ventilator settings in VC and PRVC groups are shown in Tables 2 and 3, respectively. There was significant improvement in preventilation blood $\mathrm{pH}$ in both $\mathrm{VC}$ and PRVC groups with mechanical ventilation $(P<0.001)$. Improvement in the oxygenation status as revealed by $\mathrm{PaO}_{2}$, $\mathrm{PaO}_{2} / \mathrm{FiO}_{2}$ ratio and respiratory index was significant in patients who were ventilated with PRVC mode (Table 4). There was no significant difference in variables such as $\mathrm{FiO}_{2}$ and $\mathrm{pCO}_{2}$ in before- and after-ventilation $\mathrm{ABG}$ reports in both groups. In PRVC group, mean airway pressure (Paw) was $17.5 \%$ lower as compared with VC group ( $P=0.03)$. Although no significant differences were found in PIP, Ti, and positive end-expiratory pressure (PEEP) values in two study groups. Kaplan-Meier survival test revealed that median duration of ventilation in PRVC group was $570 \mathrm{~h}$ and in VC group was $588 \mathrm{~h}$ (log-rank $P=0.83$ ).

Chest radiograph findings at admission and while patients were on ventilators did not show significant difference in two study groups (Table 5).

\begin{tabular}{|c|c|c|c|}
\hline Parameter & VC & $\begin{array}{l}\text { PRVC } \\
(n=14)\end{array}$ & $\begin{array}{l}P^{b} \\
(n=14)\end{array}$ \\
\hline $\mathrm{FiO}_{2}$ & $0.6 \pm 0.2^{a}$ & $0.56 \pm 0.19$ & 1.0 \\
\hline Vt (ml) & $117 \pm 72$ & $94 \pm 47$ & 0.2 \\
\hline $\mathrm{RR}(/ \min )$ & $26.5 \pm 6.7$ & $26.5 \pm 4.5$ & 0.8 \\
\hline PEEP $\left(\mathrm{cm} \mathrm{H}_{2} \mathrm{O}\right)$ & $5.0 \pm 1.3$ & $4.2 \pm 1.2$ & 0.07 \\
\hline PIP $\left(\mathrm{cm} \mathrm{H}_{2} \mathrm{O}\right)$ & $23 \pm 3.5$ & $20 \pm 4.1$ & 0.09 \\
\hline $\mathrm{Ti}(\mathrm{s})$ & $0.63 \pm 0.1$ & $0.52 \pm 0.06$ & 0.1 \\
\hline Paw $\left(\mathrm{cm} \mathrm{H}_{2} \mathrm{O}\right)$ & $11 \pm 2.2$ & $9.07 \pm 1.5$ & 0.03 \\
\hline
\end{tabular}

Table 2: Comparison of ABG analysis in VC and PRVC ventilation

\begin{tabular}{|c|c|c|c|c|c|c|}
\hline \multicolumn{3}{|c|}{ Preventilation } & \multicolumn{4}{|c|}{ On ventilator } \\
\hline $\operatorname{VC}(n=11)$ & PRVC $(n=12)$ & & $P^{b}$ & VC $(n=14)$ & PRVC $(n=14)$ & $P^{b}$ \\
\hline $\mathrm{FiO}_{2}$ & $0.56 \pm 0.1$ & $0.56 \pm 0.08^{a}$ & 0.6 & $0.60 \pm 0.2$ & $0.56 \pm 0.1$ & 1.0 \\
\hline $\mathrm{pH}^{2}$ & $7.2 \pm 0.08$ & $7.27 \pm 0.08$ & 0.8 & $7.39 \pm 0.06$ & $7.37 \pm 0.07$ & 0.8 \\
\hline $\mathrm{PaO}_{2}(\mathrm{mmHg})$ & $83 \pm 48$ & $65 \pm 17$ & 0.7 & $100 \pm 32$ & $98 \pm 23$ & 0.6 \\
\hline $\mathrm{PaCO}_{2}(\mathrm{mmHg})$ & $57 \pm 29$ & $49 \pm 16$ & 0.6 & $41 \pm 4$ & $43 \pm 12$ & 0.7 \\
\hline $\mathrm{PaO}_{2} / \mathrm{FiO}_{2}$ & $153 \pm 86$ & $121 \pm 41$ & 0.7 & $184 \pm 79$ & $194 \pm 81$ & 0.4 \\
\hline $\mathrm{RI}$ & $4.13 \pm 2.4$ & $4.91 \pm 2.7$ & 0.6 & $3.27 \pm 2.8$ & $3.06 \pm 2.8$ & 0.7 \\
\hline
\end{tabular}

Mean \pm SD

${ }^{b}$ Mann-Whitney test. 
Table 4: Analysis of oxygenation indices in VC ventilation and pressure-regulated VC ventilation using paired samples

\begin{tabular}{lllllll}
\hline & VC $(\boldsymbol{n}=11)$ & $\boldsymbol{P}^{b}$ & & \multicolumn{2}{c}{ PRVC $(\boldsymbol{n}=12)$} & $\boldsymbol{P}^{b}$ \\
& Preventilation & On ventilator & & Preventilation & On ventilator \\
$\mathrm{PaO}_{2}(\mathrm{mmHg})$ & $83 \pm 48^{a}$ & $96 \pm 33$ & 0.3 & $65 \pm 17$ & $99 \pm 25$ & 0.03 \\
$\mathrm{PaO}_{2} / \mathrm{FiO}_{2}$ & $153 \pm 86$ & $180 \pm 86$ & 0.2 & $121 \pm 41$ & $183 \pm 80$ \\
$\mathrm{RI}$ & $4.13 \pm 2.4$ & $3.54 \pm 3.2$ & 0.4 & $4.91 \pm 2.7$ & $3.36 \pm 2.95$ & 0.01 \\
\hline
\end{tabular}

${ }^{a}$ Mean \pm SD.

${ }^{b}$ Wilcoxan signed ranks test.

Table 5: Chest radiograph findings on admission and on ventilator

\begin{tabular}{|c|c|c|}
\hline & $\begin{array}{c}\text { VC } \\
(n=14)\end{array}$ & $\begin{array}{c}\text { PRVC } \\
(n=14)\end{array}$ \\
\hline Normal & 5 & 4 \\
\hline Aspiration pneumonia & 1 & 0 \\
\hline Collapse consolidation & 2 & 3 \\
\hline Bronchopneumonia & 4 & 2 \\
\hline Pulmonary edema & 2 & 2 \\
\hline Atelectesis & $-[3]$ & - [5] \\
\hline Diffuse infiltration & - & 1 \\
\hline Bilateral hyperinflation & - & 1 \\
\hline Lung cyst & - & 1 \\
\hline Pneumothorax & $-[1]$ & - \\
\hline VAP & $-[1]$ & $-[2]$ \\
\hline
\end{tabular}

Figures are given in parentheses.

Eight patients in VC group and eleven from PRVC group were discharged. There were three deaths in the VC group (one each of septicemia, encephalitis, and acute renal failure) and two deaths in PRVC group (subdural hematoma and cystic fibrosis). Four patients out of 28 (three from VC group and one from PRVC group) left against medical advice (two cases of bronchopneumonia and one each of Leigh disease and acute renal failure).

\section{Discussion}

We found in our study that PRVC mode is advantageous in initial stages of ventilation in sick children and it results in lower mean airway pressure and improves $\mathrm{PaO}_{2}, \mathrm{PaO}_{2} / \mathrm{FiO}_{2}$, and respiratory index as compared with $\mathrm{VC}$ ventilation. $\mathrm{VC}$ ventilation available on Siemens servo 900 machine has a constant flow pattern, whereas PRVC has the advantages of decelerating flow. ${ }^{[8]}$ PRVC ventilation is a marriage of volume and pressure ventilation controlled by the physiologic parameters of compliance. Inspiratory pressure is regulated by feedback loop to a value based on volume/pressure calculation of the previous breath compared with a preset target tidal volume. ${ }^{[3]}$ This mode theoretically combines the benefits of decelerating flow of pressure-controlled ventilation with a safety of a volume guarantee. ${ }^{[1]}$ This decelerating flow has been shown to improve oxygenation by better re- cruitment of alveoli, even distribution of ventilation, filling of alveoli with slow time constants while preventing over distension of normal alveoli, and augmenting collateral ventilation. ${ }^{[9,10]}$

There are very few reports on pediatric ventilation comparing PRVC and conventional VC ventilation. Kocis et al. ${ }^{[4]}$ compared the effects of PRVC and VC on cardiac output, airway pressure, and blood gases in the immediate postoperative period in children with congenital heart disease with minimal lung disease. This study showed significant reduction in PIP of $19 \%$ with no change in Paw when the ventilation mode was changed from VC to PRVC while $\mathrm{Ti}$, respiratory rate, and $\mathrm{FiO}_{2}$ were kept constant. There was no significant change in oxygenation status. Piotrowski et al..$^{[5]}$ compared the use of patient triggered PRVC and intermittent ventilation in neonates in a prospective randomized study and did not find any difference in PIP or oxygenation status. In the present study Paw was significantly lower in critically ill patients receiving PRVC ventilation as compared with those on VC mode with no significant difference in $\mathrm{PaO}_{2}$ (on ventilator) in two groups during initial few hours of ventilation. In other words, adequate oxygenation could be achieved with PRVC ventilation at lower Paw.

Davis et al.., ${ }^{[10]}$ in a prospective crossover study in 25 adults with acute lung injury comparing constant flow and decelerating flow, showed increase in $\mathrm{Paw}$ and $\mathrm{PaO}_{2}$ and decrease in PIP with latter. Al-saddy and Bennett ${ }^{[11]}$ reported decrease in PIP, total respiratory resistance, work of inspiration, ratio of dead space to tidal volume, and alveolar-arterial gradient for oxygen and improvement in compliance and $\mathrm{PaO}_{2}$ while comparing volumetargeted ventilation using decelerating and constant-flow patterns in adult patients. The present study shows significant improvement in oxygenation indices including $\mathrm{PaO}_{2}, \mathrm{PaO}_{2} / \mathrm{FiO}_{2}$, and $\mathrm{RI}$ with $\mathrm{PRVC}$ ventilation and not with $\mathrm{VC}$ ventilation. This may indicate advantages of decelerating flow. 
There are very few reports on the influence of specific mode of ventilation on the duration of ventilation, related morbidity, and outcome. Significantly shorter duration of PRVC ventilation was reported in neonates less than $1000 \mathrm{~g}$ only by Piotrowski et al. [5] Similar finding was not observed by the author in neonates more than $1000 \mathrm{~g}$. Rappaport et al. ${ }^{[12]}$ reported shorter duration of ventilation when pressure limited mode (decelerating flow) was compared with VC ventilation in adults but Guldagar et al. ${ }^{[13]}$ did not obtain similar results in their study. The present study did not find significant difference in duration of ventilation in two groups probably owing to small sample size.

Occurrence of ventilation-related complications such as air-leak syndromes, atelectasis, or pneumonia were not found to be different in PRVC or VC groups, though Paw were lower in former. Experimental study on isolated rabbit lung model[14] showed that Paw contributes more than tidal excursion to lung hemorrhage and lung permeability alterations induced by mechanical ventilation. Parker et al. ${ }^{[15]}$ study suggested that increased duration of the high PIP and resultant alveolar over distension is probably the injurious aspect of high Paw. Decreased incidence of intra ventricular hemorrhage was reported in neonates receiving PRVC, ${ }^{[5]}$ though no similar observation was reported for pneumothorax.

We believe that the present study is the first to compare the use of PRVC and VC ventilation modes in sick children with lung disease owing to varied clinical diagnosis admitted in the PICU of a developing country. This study is different from previous studies that no experimental manipulation of ventilator parameters was done, as would be the characteristic of a prospective study. But the sample size in this study is small, owing to which comparison in different age groups or specific disease or influence of ventilation mode on duration or related complications could not be done. This study is focused on the benefits of PRVC mode in the initial ventilation. The preventilation $\mathrm{PaO}_{2}$ and $\mathrm{PaO}_{2} / \mathrm{FiO}_{2}$ ratio in $\mathrm{VC}$ group of patients appears better than that of PRVC group. This difference was not found to statistically significant $(P=$ 0.7). PIP rather than plateau pressure was recorded which has its own limitation. ${ }^{[4]}$ Because all our patients were sedated and paralyzed, these results may not be extrapolated to patient-triggered modes.
We conclude that although PRVC mode supports benefits in initial ventilation, a prospective crossover study with a large number of patients with a specific lung disease is needed to assess the advantages of PRVC ventilation, its effect on oxygenation, related complications, and outcome.

\section{Reference}

1. Marrow AG. Innovative practices of ventilatory support with pediatric patients. Pediatric Crit care Med 2003;4:8-20.

2. Kucmorek R, Custer JR, Fugate JH. Mechanical ventilation In Critical care of infants and children.Ed.Todres ID, Fugate JH. Little Browne and Company: New York; 1996. p. 155-82.

3. Apostolacos MJ, Levy PC, Papdakos PJ. New modes of mechanical ventilation. Clin Pulm Med 1995;2:121-8.

4. Kocis KC, Dekeon MK, Rosen HK, Bandy KP, Crowley DC, Bove $E L$, et al. Pressure regulated volume control vs. volume control ventilation in infants after surgery for congenital heart disease. Pediatr cardiol 2001;22:233-7.

5. Piotrowski A, Sobala W, Kawczynski P. Patient-initiated pressure regulated volume controlled ventilation compared with intermittent mandatory ventilation in neonates: a prospective randomized study. Intensive Care Med 1997;23:975-81.

6. Pollack MM, Patel KM, Ruttimann UE. Prism III: an updated Pediatric Risk of Mortality Score. Crit Care Med 1996;24:74352.

7. Gowda MS, Klocke RA. Variability of indices of hypoxemia in adult respiratory distress syndrome. Crit Care Med 1997;25:41-

8. Servo ventilator 300/300A- operating manual 8.0/9.0 SiemenElema AB, Electromedical Systems Division, S- 17195 Solna, Sweden.

9. Abraham E, Yoshihara G. Cardiorespiratory effects of pressure controlled ventilation in severe respiratory failure. Chest 1990;98:1445-9.

10. Davis K, Branson DR, Campbell RS, Porembka DT. Comparison of volume control and pressure control ventilation: Is flow waveform the difference? J Trauma 1996;41:808-14

11. Al-Saddy N, Bennett E. Decelerating inspiratory flow waveform improves lung mechanics and gas exchange in patients on intermittent positive pressure ventilation. Intensive Care Med 1985;11:68-75.

12. Rappaport SH, Shipner R, Yoshihara G, Wright J, Chang R, Abraham E. Randomized, prospective trial of pressure-limited versus volume controlled ventilation in severe Respiratory failure. Crit Care Med 1994;22:22-32.

13. Guldager H, Nielsen SL, Carl P, Soerensen MB. A comparison 
of volume control and pressure regulated volume control ventilation in acute respiratory failure. Crit Care 1997;1:75-7.

14. Broccard AF, Hotchkiss JR, Suzuki SO, Olson D, Marini JJ. Effects of mean airway pressure and tidal excursion on lung injury induced by mechanical ventilation in an isolated perfused rabbit lung model. Crit Care Med 1999;27:1533-41.

15. Parker JC, Hernandez LA, Peevy KJ. Mechanisms of ventilator - induced lung injury. Crit Care Med 1993;21:131-43. 